\title{
Characterization of Copolymer Based in Polyurethane and Polyaniline (PU/PANI)
}

\author{
Norma Aurea Rangel-Vázquez, ${ }^{1}$ René Salgado-Delgado, ${ }^{2}$ Edgar García-Hernández, ${ }^{2}$ \\ and Ana María Mendoza-Martínez ${ }^{3}$ \\ 1 Departamento de Metalmecánica del Instituto Tecnológico de Querétaro, Avenida Tecnológico y M. Escobedo Col. Centro \\ CP. 76000, Querétaro, Querétaro, México.norma_rangel79@yahoo.com.mx. Tel (01-52) 4421911840 \\ 2 División de Estudios de Posgrado e Investigación del Instituto Tecnológico de Zacatepec. Calzada Instituto Tecnológico \\ Num. 27, Col. Ampliación Plan de Ayala, CP. 62780 Zacatepec, Morelos, México. \\ 3 División de Estudios de Posgrado e Investigación del Instituto Tecnológico de Ciudad Madero. Juventino Rosas S/N, \\ Col. Los Mangos, Cd. Madero, Tamaulipas, México.
}

Received September 12, 2009; accepted January 28, 2010

\begin{abstract}
The present work describes the synthesis and characterization of polyurethane (PU), polyaniline (PANI) and three IPNs $(90 / 10,80 / 20,70 / 30)$ ratios were characterized by Fourier transformed infrared (FTIR) to analyze the generated functional groups of the synthesis. The combination PU/PANI was accomplished through the interconnection of the two polymers via condensation of PU prepolymer terminal NCO groups and the amine groups of PANI. DMA studies indicated that the PU had higher glass transition temperatures $(\mathrm{Tg})$ with the increase of PANI. SEM micrographics were obtained to $1000 \mathrm{X}$ of the PU, PANI and the ratios $90 / 10$, $80 / 20$ and $70 / 30$ of PU/PANI. A morphological interpretation was proposed in which PANI chains formed a phase dispersed in a PU matrix, linked together by an interphase, that could be responsible for the connectivity between the two polymers and determine excellent mechanical properties.

Key words: Polyurethane, Polyaniline, IPN, FTIR, DMA, SEM.
\end{abstract}

\section{Introduction}

Conductive polymers are widely studied because of their foremost properties such as high conductivity to weight ratio, corrosion resistence and facile processibility. Conducting polymers exhibit special properties compared to metals in the sense that they do not only reflect but also selectively absorb electromagnetic radiations. Various conductivities with radiation frequency have made them useful in radar absorbing materials. Conducting polymer as molecular wires is an excellent choice because of their long $\pi$-conjugation length as well as their high metal conductivity [1]. In recent years, polymer-polyaniline (PANI) conductive polymeric composites have received considerable attention because of their potential applications in electrodes, biosensors, batteries, antistatic coatings, gas sensors, membranes and light emitting diodes [2-14] PANI is a conducting polymer [15] which has been extensively studied due to its relatively high conductivity and potential application in electronic devices. The general formula for ideal PANI materials in their base forms consists in three $\left(-\mathrm{C}_{6} \mathrm{H}_{4}-\mathrm{NH}-\right)$ benzenoid units and one $\left(-\mathrm{N}=\mathrm{C}_{6} \mathrm{H}_{4}=\mathrm{N}-\right)$ quinoid unit [16].

The y value accounts for the oxidation state of the polymer. Leucoemeraldine base (LEB), emeraldine base (EB)
Resumen. El presente trabajo describe la síntesis y caracterización del Poliuretano, (PU), Polianilina (PANI) y tres IPNs (90/10, 80/20, 70/30). Estos materiales fueron caracterizados mediante espectroscopia de infrarrojo por transformadas de Fourier (FTIR) para analizar los grupos funcionales generados de la síntesis. La combinación PU/ PANI se llevó a cabo a través de la interconexión de los dos polímeros vía condensación de grupos de NCO terminales del prepolímero de PU y las aminas de la PANI. Los estudios de DMA indicaron que el PU presentó temperaturas de transición vítreas (Tg) mayores con el incremento de PANI. Se obtuvieron las micrografías de SEM a 1000X del PU, PANI y las relaciones 90/10, 80/20 y 70/30 de PU/PANI, en donde, las cadenas de PANI formadas se dispersaron en la matriz de $\mathrm{PU}$, se produjo una interfase, la cual fue la responsable de la conectividad entre los dos polímeros y determinaron excelentes propiedades mecánicas.

Palabras claves: Poliuretano, polianilina, IPN, FTIR, DMA, SEM.

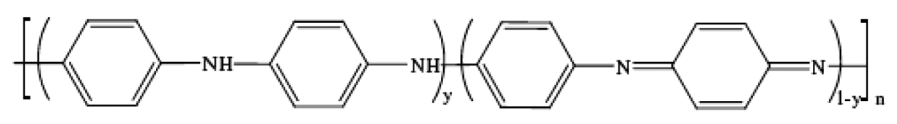

and pernigraniline base (PNB) correspond to the completely reduced $(y=1)$, half oxidized $(y=0.5)$ and completely oxidized $(y=0)$ states, respectively. Whereas the three bases are insulating materials, base protonation leads to the corresponding salts.

Emeraldine salt (ES) is the only one exhibiting high electric conductivity and has consequently received considerable interest [16-17]. With PANI emeraldine salts a range of anions, including polyelectrolytes and functional molecules, can be incorporated as dopants. However, the range of dopants that can be directly incorporated is limited due to the fact that an acidic environment must be used to induce aniline solubility in aqueous media and to maintain the polymer in the conductive emeraldine salt form during growth [18]. A conducting polymer blend with PANI and conventional polymer can exhibit good mechanical properties associated with interesting electrical properties. However, blending has very little effect on the environmental stability of the conducting polymer itself. One of the major limitations of the blending is that it almost 
always produces a highly heterogeneous two-phase morphology. Therefore, it may be more effective to prepare a conducting polymer with improved processibility and mechanical property by the chemical synthesis approach. The combination of PANI segments with blocks of another polymer has been recently reported, such as the grafting of polyethylene glycol or polyacrylic acid onto a PANI backbone, and a block copolymer consisting of PU and PANI oligomer, etc. The use of a thermoplastic elastomer with conducting polymers is very attractive due to the combination of mechanical properties and a processability which does not require vulcanization [16]. The reason why PU is chosen is due to its balanced flexibility and hardness, good film forming property and resistance to solvent. Moreover, the interaction between NH in PANI and NHCOO in PU may be a bonus to improve the compatibility of the system. The strong tendency of PANI and PU to form hydrogen bonding has been verified by Rodrigues through various spectroscopic techniques, which was believed to be responsible for a certain degree of phase mixing in PANI/PU blend. Ho and coworkers also confirmed the hydrogen bonding between PANI and PU, and the stronger hydrogen bonding in the blend contributed to better miscibility, higher conductivity and tensile strength.

In the characterization of PANI filled PU/PMMA interpenetrating network system, Siddaramaiah mentioned that the hydrogen bonding formation between NH of PANI and NHCOO group of PU/PMMA polymer network had some effect on the physicomechanical, electrical as well as thermal properties of the conducting IPN. Yoshikawa et al. also suggested that the interaction between the carboxyl groups in PU and imine groups in PANI could induce miscibility of PANI/ PU blends $[16,19]$. IPNs were prepared by sequential method. Functional groups, microstructure and mechanical properties of three PU/PANI ratios $(90 / 10,80 / 20,70 / 30)$ are reported here.

\section{Results and discussion}

\subsection{Fourier Transfer Infrared Spectroscopy}

The IR spectra of three PU/PANI ratios are shown in figure 1. In all of the spectra, the strong peak around $3350 \mathrm{~cm}^{-1}$ comes from the stretching vibration of $\mathrm{N}-\mathrm{H}$ bond in the urethane segments. The formation of PANI was revealed by the absorption bands at $3460,1603,1179,1124$ and $834 \mathrm{~cm}^{-1}$, which were attributed to the vibrations of $\mathrm{N}-\mathrm{H},-\mathrm{C}=\mathrm{C}-, \mathrm{Ph}-\mathrm{NH}, \mathrm{Ph}-\mathrm{NH}-$ $\mathrm{Ph}$, and $\mathrm{C}-\mathrm{N}$ in the aniline unit [10]. Bands corresponding to urethane $\left(-\mathrm{CH}_{2}\right.$ a $2926-2907 \mathrm{~cm}^{-1}, \mathrm{CH}_{3}$ a $2851-2841 \mathrm{~cm}^{-1}$ y $\mathrm{C}=\mathrm{O}$ a $1725-1701 \mathrm{~cm}^{-1}$ ) can be observed [20-22], and the peak at about $1600 \mathrm{~cm}^{-1}$ corresponds to $\mathrm{C}=\mathrm{C}$ stretching peak in the benzene and quinoide rings $[13,16]$. Two peaks at 1510 and $1012 \mathrm{~cm}^{-1}$ arise from symmetric and asymmetric stretching vibration of $\mathrm{N}-\mathrm{C}-\mathrm{N}$ in the urethane-aniline, corresponding to the reactions of the $-\mathrm{NCO}$ groups with the $\mathrm{NH}_{2}$ groups of the PANI [16].

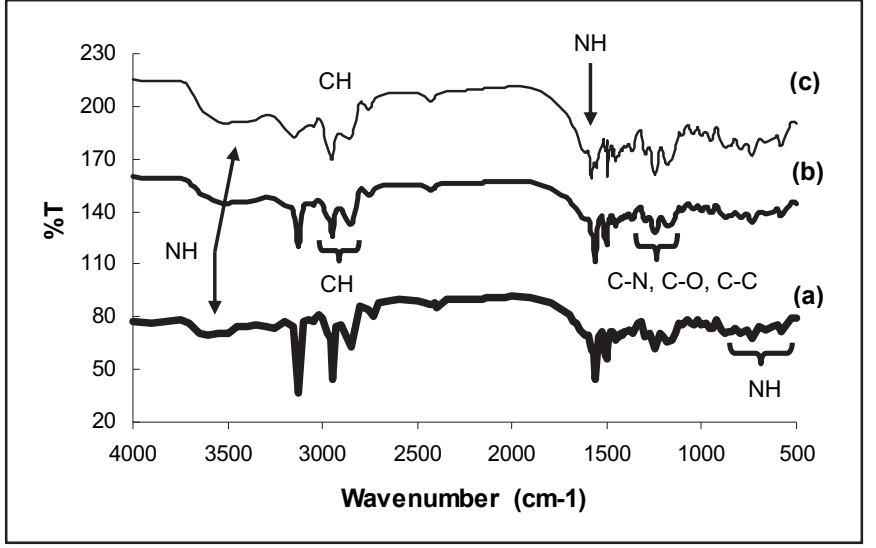

Fig. 1. IR spectra of three PU/PANI ratios, (a) 90/10, (b) $80 / 20$ y (c) $70 / 30$, respectively

In the region below $2000 \mathrm{~cm}^{-1}$ the spectrum exhibits two main bands, with maxima situated at 1574 and $1488 \mathrm{~cm}^{-1}$, assigned to quinonoid and benzenoid ring stretching vibrations, respectively $[13,23]$ while the bands at 1315 and $1244 \mathrm{~cm}^{-1} \mathrm{can}$ be attributed to $\mathrm{C}-\mathrm{H}$ stretching vibration with aromatic conjugation, and the absorption peak near $1160 \mathrm{~cm}^{-1}$ results from the $\mathrm{N}=\mathrm{Q}=\mathrm{N}$ ( $\mathrm{Q}$ denotes quinoid ring) stretching mode [23]. Two small peaks at 1034 and $1006 \mathrm{~cm}^{-1}$ are ascribed to the $\mathrm{SO}_{3} \mathrm{H}$ groups after doped with ACS. The broader absorption around $1100 \mathrm{~cm}^{-1}$ accompanied by a shoulder at ca. $1080 \mathrm{~cm}^{-1}$ can be attributed to the $\mathrm{C}-\mathrm{O}-\mathrm{C}$ stretching vibrations. The absorption band at $1309 \mathrm{~cm}^{-1}$ corresponds to $\pi$-electron delocalization induced in the polymer by protonation [24-25]. A band characteristic of the conducting protonated form is observed at $1223 \mathrm{~cm}^{-1}$ and it is interpreted as a $\mathrm{C}-\mathrm{N}^{+}$stretching vibration in the polaron structure. The prominent $1149 \mathrm{~cm}^{-1}$ band has been assigned to a vibration of the $-\mathrm{NH}^{+}=$structure, which is formed during protonation [26-27]. A small band at $1167 \mathrm{~cm}^{-1}$ is observed in its place. The region of $1010-1170 \mathrm{~cm}^{-1}$ belongs to the aromatic $\mathrm{C}-\mathrm{H}$ in-plane bending modes. Out-of-plane deformations of $\mathrm{C}-\mathrm{H}$ on substituted aromatic rings are located in the region of $800-880 \mathrm{~cm}^{-1}$. Combining the above results, it is concluded that the PU/PANI have been successfully prepared. Furthermore, the absorptions at 1734 and $1707 \mathrm{~cm}^{-1}$ are assigned to non-bonded and hydrogen-bonded urethane carbonyl $\mathrm{C}=\mathrm{O}$ stretching, respectively. It is noteworthy from the spectra that the higher the PANI content is contained in the PU hybrid, the stronger the hydrogen-bonded carbonyl group is observed. Clearly, the incorporated PANI molecules in the hybrids have groups being able to induce hydrogen bonding and can alter the ratio of free vs. H-bonded urethane carbonyl groups of Pus $[14,16]$.

\subsection{Dynamic Mechanic Analysis}

DMA was used to study the dynamic mechanical behavior of IPNs Figures 2 and 3 shows storage modulus for PU, PANI and PU/PANI $(90 / 10,80 / 20,70 / 30)$ as function of tempera- 


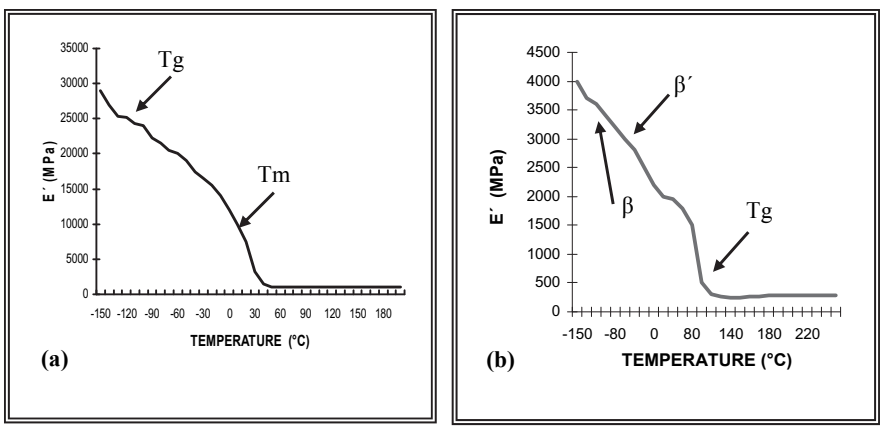

Fig. 2. DMA spectra of (a) PU and (b) PANI, respectively

ture respectively. For PU (figure 2a), a decrease in modulus occurred at the PU (around $-90{ }^{\circ} \mathrm{C}$ ) was attributed to the glass transition of the film containing residual NMP since an abrupt decrease in storage modulus occurred in this region. A secondary transition around $50{ }^{\circ} \mathrm{C}$, related to the $\mathrm{CH}_{2}-$ motion of the HDI sequences of the PU segments. The DMA data indicate that the PUs based NMP can exhibit higher temperature resistance. The dynamical mechanical analysis (DMA) spectrum of the pure PANI is shown in Figure $2 \mathrm{~b}$. Three relaxation processes were detected: a peak at $-95{ }^{\circ} \mathrm{C}$ $(\beta)$; a shoulder $\left(\beta^{\prime}\right)$ at $-60^{\circ} \mathrm{C}$ and the glass transition at 90 ${ }^{\circ} \mathrm{C}$. The widths of $\beta$ and $\beta^{\prime}$ are related to different degrees of water or NMP solvation in the film and were attributed to the relaxation of aromatic rings and/or of solvent molecules bound to the polymer chain. The location of Tg is in accordance with reported data for PANI plasticized with NMP [28-30].

The network spectra were recorded for PU/PANI ratios of 90/10, 80/20 and 70/10 (Figure 3). For the three networks, the PU glass transition shifted from $-90{ }^{\circ} \mathrm{C}$ (pure PU, figure 2(a)) to $-110^{\circ} \mathrm{C}$, and a peak at $48{ }^{\circ} \mathrm{C}$ was ascribed to the relaxation of an interphase formed between PU/PANI polymers, the shoulder at $95.7^{\circ} \mathrm{C}$ was assigned to the glass transition of PANI, which was shifted to higher temperatures as compared with the free PANI, due to crosslinking [28].

Shifts of the carbonyl and -NH- absorption in the infrared, along with the presence of a new relaxation in the DMA spectra strongly suggested the presence of an interphase, which would be responsible for the connectivity between the PU and PANI phases and for the resulting good mechanical properties. Qi et al (2008) used dynamic mechanical and dielectric thermal analyses together with infrared spectroscopy to identify molecular motions in PANI films cast from emeraldine base powder dissolved in the solvent NMP. These relaxations include a librational ring motion at around $-80{ }^{\circ} \mathrm{C}$ and a glass transition $(\mathrm{Tg})$ centred at $100{ }^{\circ} \mathrm{C}$. They have also observed a permanent film hardening process at around $180^{\circ} \mathrm{C}$ which is ascribed to polymer chain crosslinking, both physical (associated with chain entanglements) and more importantly chemical (chain-chain chemical bonding). Chemical crosslinking can be further identified with chain defects and residual impurities in the polymeric material. The
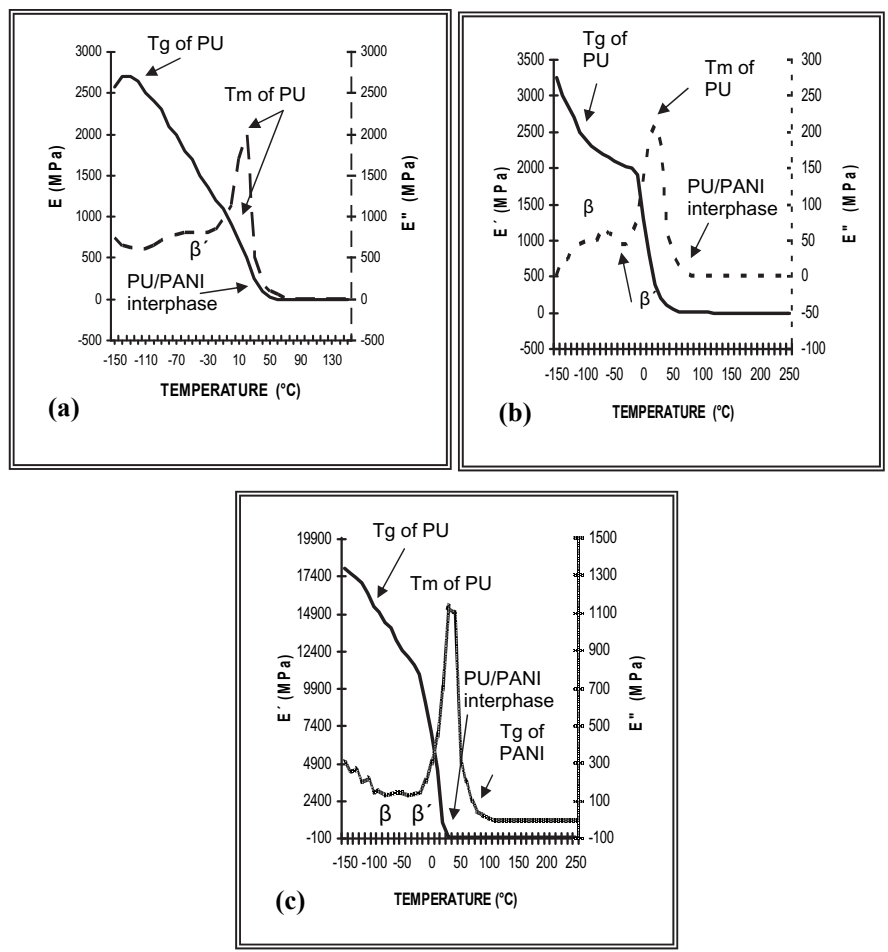

Fig. 3. DMA network spectra for PU/PANI ratios of (a) $90 / 10$, (b) $80 / 20$ and $70 / 30$, respectively

importance of precise control of PANI synthesis and processing is therefore strongly emphasised. These results have clear implications for the thermal orientation process in PANI [31]. Melo et al (2008) pointed out this $\beta$ relaxation in the region of $-80 /-60{ }^{\circ} \mathrm{C}$. By doing analysis on annealed samples, they have shown that $\beta$ is linked to the residual content of water (from the film fabrication, moisture) in the films. So, the most probable hypothesis for Melo et al. would be the rotation of water molecules which are hydrogen bonded to the polymeric chain. Water molecules would act as side units of the polymer chain and become responsible for this relaxation. It could be linked to different phenomena especially to the presence of solvents containing a $\mathrm{C}=\mathrm{O}$ bound (like NMP). Some authors have reported that the residual solvent (NMP) could exist in two forms in the polymeric material; free and hydrogen bonded NMP. Indeed, NMP can form hydrogen bond between the $\mathrm{C}=\mathrm{O}$ present in its structure and the $\mathrm{NH}$ group present in PANI [32].

\subsection{Scanning Electronic Microscopy}

The morphologies of pure PU and PANI are shown in figure 4, respectively. The SEM micrograph of PU reveals a smooth continuous phase; some bumps appear on the micrograph, due to that the picture was taken from the fractured part of the polymer. Also, it can be seen the PANI form a homogeneous network, that which is a characteristic that causes the plastificant (NMP) during the synthesis, and it coincided 

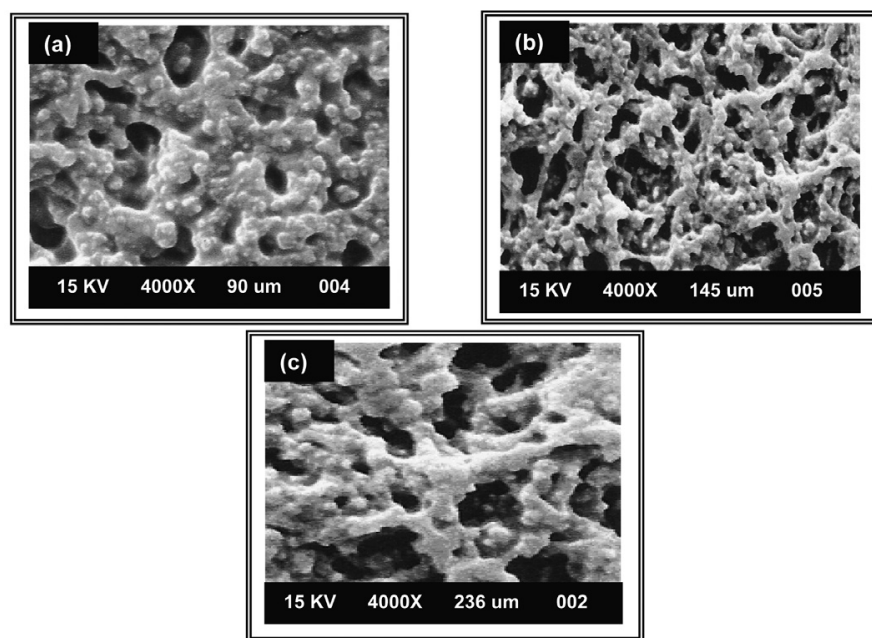

Fig. 4. SEM micrographs where (a) 90/10, (b) 80/20 and (c) 70/30 of PU/PANI, respectively

with that reported by Nabid et al [33] who also appreciated that the PANI surface presented a fibrial morphology with the extraction of NMP due to THF. Figure 4(c) displays the morphology of IPN with PANI contents of $30 \%$. This micrograph indicates that the PANI primary particles disperse among the PU matrix, and coalesce to form aggregates. More aggregates are formed in the IPN as the PANI content increases from $10 \%$ to $30 \%$. Furthermore, in the $90 / 10$ ratio, the IPN structure is more compact that is to say, the cells are closed in comparison with the $80 / 20$ and $70 / 30$ ratios where the cells are open.

\section{Conclusions}

It was possible to prepare IPNs based in PU, PANI and PU/ PANI ratio in 3 levels. The interconnection of PANI chains through PU segments has originated a series of new semi-conducting materials with good mechanical properties. By FTIR was possible to detect characteristic signals of PU, PANI, the relative intensity of the 1740 and $1660 \mathrm{~cm}^{-1}$ absorptions in the blends is changed as compared to the networks: in the blends the latter is less intense than in the networks. This result was attributed to the inclusion of the absorption of the carbonyl group resulting from the new urea type bond PANI/PU in the networks, along with the presence of a new relaxation in the DMA analysis two Tgs were detected for the samples, corresponding to PU and PANI networks, which suggest phase separation in a macroscopic level, characteristic of semi-IPN. $\mathrm{Tg}$ values shifted inward its respective polymer as PU/PANI ratio was changed. Trough SEM, the samples showed some characteristics of phase separation, which are proper of IPNs. Therefore when PU or PANI increased in the materials, these presented a heterogeneous surface, due to the control of one of the individual components.

\section{Experimental}

\subsection{Materials}

1,6-Hexanediol (Molecular weight $118.17 \mathrm{~g} / \mathrm{gmol}$, Fluka), $\mathrm{N}$-methyl pyrrolidine (Molecular weight $85.15 \mathrm{~g} / \mathrm{gmol}$, Aldrich), HDI (Molecular weight $168.2 \mathrm{~g} / \mathrm{gmol}$, Fluka), Isopropanol (Molecular weight $60.10 \mathrm{~g} / \mathrm{gmol}$, Sigma-Aldrich), Aniline (Molecular weight $93.126 \mathrm{~g} / \mathrm{gmol}$, Sigma-Aldrich), Ammonium persulphate (Molecular weight $228.20 \mathrm{~g} / \mathrm{gmol}$, Fluka), Clorhidric acid (Molecular weight $36.46 \mathrm{~g} / \mathrm{gmol}$, Sigma-Aldrich), Sodium hydroxide (Molecular weight 35.10 g/gmol, Aldrich).

\subsection{Methods}

Synthesis of Polyurethane (PU), N-methyl pyrrolidine was dissolved in 1,6-hexanediol with an excess from HDI at $65^{\circ} \mathrm{C}$ in nitrogen atmosphere during $3 \mathrm{~h}$, finally, to carry out the reaction, the isopropyl alcohol was added.

The synthesis of Polyaniline (PANI) was prepared by oxidative polymerization of aniline. The solution of $0.2 \mathrm{M}$ aniline $\left(\mathrm{C}_{6} \mathrm{H}_{5} \mathrm{NH}_{2}\right)$ and $0.1 \mathrm{M}$ ammonium persulphate $\left(\left(\mathrm{NH}_{4}\right)_{2} \mathrm{~S}_{2} \mathrm{O}_{8}\right)$ mixed with $1 \mathrm{M} \mathrm{HCl}$ aqueous solution respectively, were individually kept in a refrigerator during $1.2 \mathrm{~h}$ with a controlled temperature $\left(5^{\circ} \mathrm{C}\right)$. Then the solution was filtered, the precipitate was washed with $\mathrm{HCl}$, placed in $\mathrm{NH}_{4} \mathrm{OH}$ and upset during $16 \mathrm{~h}$. The solution was again filtered and the obtained polymer was dried during $2 \mathrm{~h}$, finally, to the obtained pasta was added $\mathrm{NH}_{4} \mathrm{OH}$ [34-35].

Synthesis of PU/PANI network was carried out through the reaction between the PU chains by means of the NCO groups and the PANI dissolved in NMP, where the concentrations (PANI) were 10, 20 and $30 \% \mathrm{~m} / \mathrm{m}$. The reaction time was $6 \mathrm{~h}$. Later on, the materials were doped by means of camphorsulfonic acid (CSA) (see figure 5). Finally, at the end of the reaction, the product obtained was poured in teflon badges and cured at $72{ }^{\circ} \mathrm{C}$.

\subsection{Characterization}

The FTIR spectra of various samples in $\mathrm{KBr}$ pellets were obtained using a Perkin Elmer-FTIR instrument with a resolution of $4 \mathrm{~cm}^{-1}$. The average of 16 scans was used to obtain each spectrum. All samples were vacuum-dried overnight prior to measurement [34].

Dynamic Mechanical Analysis (DMA) was performed on a TA Instrument 2980 dynamic mechanical analyzer under multifrequency mode at a temperature range of -1500 to 250 ${ }^{\circ} \mathrm{C}$ (heating rate $5^{\circ} \mathrm{C} / \mathrm{min}$ ), and a fixed frequency of $1 \mathrm{~Hz}$ using a dual cantilever clamp.

Scanning electron microscopy (SEM) was performed for sample micro-structural analysis on an electron microscope Joel JSV 5800 LV model. The voltage of acceleration was of $15 \mathrm{Kw}$ [36]. 

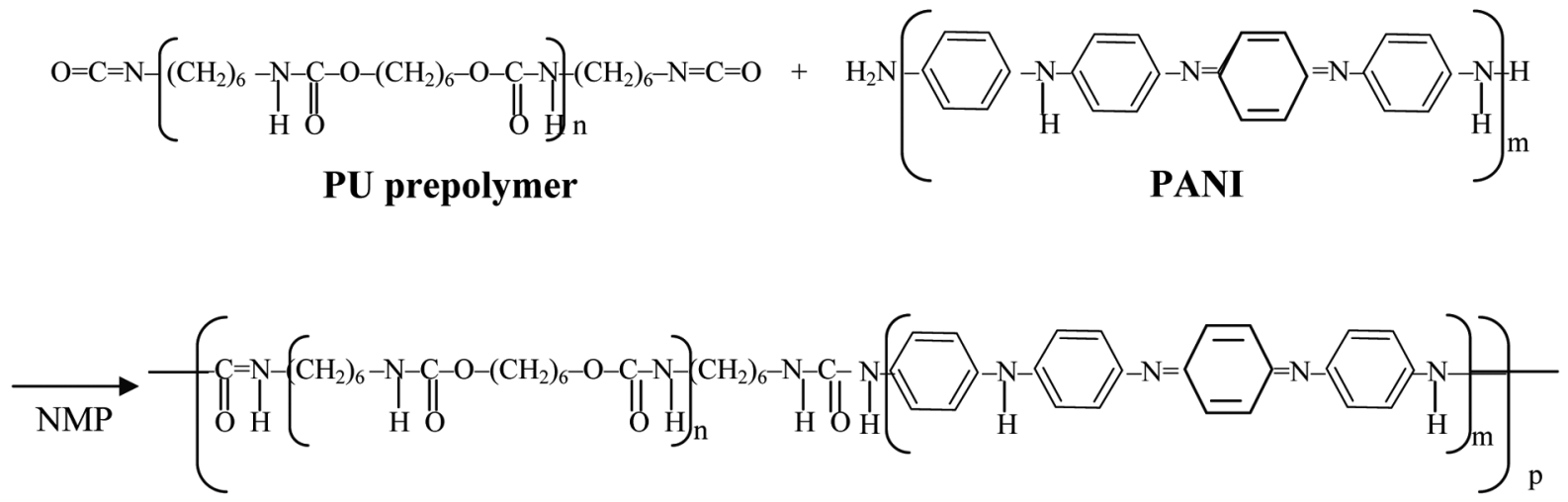

PU / PANI

Fig. 5. Synthetic route for the preparation of PU/PANI

\section{Acknowledgements}

To DGEST for scholarship.

\section{References}

1. Wai, P. S.; Tadokoro, M.; Watanabe, J.; Kuramoto, N. Synth. Met. 2008, 158, 251-258.

2. Mo, Z. L.; Zhao, Z. L.; Chen, H.; Niu, G. P.; Shi, H. F. Carbohyd. Polym. 2009, 75, 660-664.

3. Baker, C. O.; Shedd, B.; Innis, P. C.; Whitten, P. G.; Spinks, G. M.; Wallace, G. G.; Kaner, R. B. Mater. Sci. Eng. B, 2009, 162, 111-115.

4. Antonel, P. S.; Andrade, E. M.; Molina, F. V. React. Funct. Polym. 2009, 69, 197-205.

5. Prabhakar, N.; Sumana, G.; Arora, K.; Singh, H.; Malhotra, B. D. Electrochim. Acta 2008, 53, 4344-4350.

6. Huang, L.; Zhuang, X.; Hu, J.; Lang, L.; Zhang, P.; Wang, Y.; Chen, X.; Wei, Y.; Jing, X. Biomacromolecules 2008, 9, 850-858.

7. Gloukhovski, R.; Oren, Y.; Linder, C.; Freger, V. J. Appl. Electrochem. 2008, 38, 759-766

8. Zhang, H.; Zong, R.; Zhao, J.; Zhu, Y. Environ. Sci. Technol. 2008, 42, 3803-3807.

9. Chaudhari, S.; Patil, P. P. J. Appl. Polym. Sci. 2008, 109, 25462561.

10. Lee, H. Y.; Rwei, S. P.; Wang, L.; Chen, P. H. Mater. Chem. Phys. 2008, 112, 805-809.

11. Chen, J.; Xu, Y.; Zheng, Y.; Dai, L.; Wu, H. Compt. Rend. Chim. 2008, 11, 84-89.

12. Lu, Y.; Wang, L.; Zhao, B.; Xiao, G.; Ren, Y.; Wang, X.; Li, C. Thin Solid Films 2008, 516, 6365-6370.

13. Kalasad, M. A.; Gadyal, R. K.; Hiremath, I.; Ikram, M.; Mulimani, B. G.; Khazi, I. M.; Krishnan, S. K.; Rabinal, M. K. Compos. Sci. Technol. 2008, 68, 1787-1793.

14. Ji, S.; Li, Y.; Yang, M. Sensor. Actuat. B 2008, 133, 644-649.

15. Amado, F. D. R.; Rodrigues, M. A. S.; Morisso, F. D. P.; Bernardes, A. M.; Ferreira, J. Z.; Ferreira, C. A. J.Colloid Interf. Sci. 2008, 320, 52-61.

16. Wang, T. L.; Yang, C. H.; Shieh, Y. T.; Yeh, A. C. Eur. Polym. J. 2009, 45, 387-397.

17. Ando, R. A.; Do Nascimento, G. M.; Landers, R.; Santos, P. S.; Spectrochim. Acta A 2008, 69, 319-326.
18. Masdarolomoor, F.; Innis, P. C.; Wallace, G. G. Electrochim. Acta, 2008, 53, 4146-4155.

19. Luo, J.; Wang, X.; Li, J.; Zhao, X.; Wang, F. Polymer 2007, 48, 4368-4374.

20. Gómez-Jiménez, M. A.; Rivera-Armenta, J. L.; MendozaMartínez, A. M.; Robledo- Muñiz, J. G.; Rangel-Vazquez, N. A. Terres-Rojas, E. Lat. Amer. Appl. Res. 2009, 39, 131-136.

21. Ma, J.; Li, Q.; Song, B.; Liu, D.; Zheng, B.; Zhang, Z.; Feng, Y. J. Mol. Catal. B 2009, 56, 151-157.

22. Wang, X. L.; Mou, Y. R.; Chen, S. C.; Shi, J.; Wang, X. L.; Wang, Y. Z. Eur. Polym. J. 2009, 45, 1190-1197

23. Zhou, C.; Han, J.; Song, G.; Guo, R. Eur. Polym. J. 2008, 44, 2850-2858.

24. Ede ¡nkova', I.; Trchova, M.; Stejskal, J. Polym. Degrad. Stabil. 2008, 93; 2147-2157.

25. Kuo, C. W.; Wen, T. C.; Eur. Polym. J. 2008, 44; 3393-3401.

26. Bleda M. M. J.; Peng, C.; Zhang, S.; Chen, G. Z.; Morallón, N. E.; Cazorla, A. D. J. Electrochem. Soc. 2008, 155, A672-A678

27. Camilo, F. F.; Faez, R.; Bizeto, M. A.; Correa, C. M.; $11^{\text {st }}$ International Conference on Advanced Materials, Río de Janeiro, Brazil 2009.

28. Romo-Uribe, A.; Arizmendi, L.; Romero-Guzman, M. E.; Sepulveda-Guzman, S.; Cruz-Silva, R. ACS Appl. Mater. Interfaces 2009, 1, 2502-2508.

29. Hall, S. MS Engineering: Materials Science, 2009, University of Cincinnati, USA

30. Aykanat, A. PhD Engineering: Materials Science, 2008, University of Cincinnati, USA

31.Lee, L. W. Doctor of Philosophy, Chemistry, 2008, University of Akron USA

32. Qi, Y. N.; Xu, F.; Sun, L. X. J. Therm. Anal. Calorim. 2008, 94, 137-141.

33. Oliveira-Melo, L.; Ponzio, E. A.; Carmona-Ribeiro, A. M.; Torresi, R. M. E-Polymers, 2008, 149, 111-114.

34. Reza-Nabid, M.; Golbabaee, M.; Bayandori-Moghaddam, A.; Dinarvand, R.; Sedghi, R. Int. J. Electrochem. Sci., 2008, 3, 1117 $-1126$.

35. Kumar, S.; Singh, V.; Aggarwal, S.; Mandal, U. K. Soft Mater. 2009, 7, 150-163.

36. Amaya, T.; Saio, D.; Hirao, T. Macromol. Complex. 2008, $270,88-94$. 